\title{
WILMS’ EMBRYOMA
}

\author{
A Clinico-Pathological Study
}

BY

RUBY O. STERN, M.D.

Sebag-Montefiore Research Fellow, The Hospital for Sick Children, Great Ormond Street

AND

G. H. NEWNS, M.D., M.R.C.P.

Medical Registrar and Pathologist, The Hospital for Sick Children, Great Ormond Street.

The malignant growths variously called ' Wilms' tumours, adeno-sarcomata, embryomata or nephroblastomata are among the most frequent of those occurring in childhood.

Wilms in 1899 in his valuable monograph was the first to explain the etiology of these tumours on an embryological basis, and by his analysis of fifty-one cases established the group as a definite entity. He was not, however, the first to describe the tumour, for forty-six of the cases to which he referred had been published by others, notably by Birch-Hirschfeld (1898), who reported four cases ; Heineke (1897), who reported nine cases ; Perthes (1896), three cases; and Ribbert (1892), four cases. All these authors recognized the peculiar 'mixed' structure of these tumours and called them rhabdo-myosarcoma, adeno-sarcoma, embryonal adeno-sarcoma (Birch-Hirschfeld).

The terminology and the origin of these neoplasms have been much in dispute and the subject of much controversy. Although everyone who has studied them agrees that they are embryonal in that they arise in the region of the developing kidney, there are at least two conflicting views as to their precise origin. It is obvious that the constituent cells of these tumours must be formed either very early or very late in the process of development of the kidney. They cannot arise from the Wolffian body, as this does not take part in the formation of the permanent kidney; and the frequent presence of immature glomeruli and fully-formed tubules in these tumours indicates that they originate either very early in embryonic life, from a multipotential cell, or at a much later stage, from the metanephros in which the glomeruli and tubules of the permanent kidney develop. The former alternative, expounded in 1899 by Wilms, is the 
generally accepted view. Wilms postulated that at an early stage in development of the Wolffian ridge undifferentiated cells are present which can give rise to the cells of the nephrotome, the myotome and the sclerotome. That is to say, they differentiate into cells which form the kidney, muscle, and cartilage. Some of these undifferentiated cells become concentrated at the site of the developing kidney and there give rise later to tumour masses in which may be found muscle fibres and cartilage.

Directly opposed to this view is that of Busse (1899), whose opinion has recently been supported by Nicholson (1931). Busse considered that these tumours arose from the metanephros at a late stage in development and that the more primitive cells found in them resulted from metaplasia. Nicholson, in accepting this view, regarded the presence of glomeruli as evidence of a metanephric origin. His opinion is that in differentiation and co-relation of its several parts this embryonal tumour resembles, and represents, the developing kidney. As, however, it grows without subserving any useful function it is, and remains, $a$ 'tumour ' and is best described as a 'tumour malformation.'

This view cannot explain the presence in these tumours of the muscle fibres which have been reported in a fairly high proportion of cases by various authors. (McCurdy found them in 37 per cent. of his cases.) Another objection to this view is the fact that the tumours are seldom in or incorporated with the kidney. They are nearly always separated from the kidney by a definite fibrous capsule, and although the kidney may be stretched over the tumour, infiltration of the kidney substance is uncommon. If these tumours are to be regarded as part of the developing kidney it would be expected that they should be incorporated in the kidney substance and situated in the interior of that organ. These objections make it difficult to accept this view of their origin.

The nomenclature may be said to be varied if not apt, although the timehonoured custom of attaching the name of a discoverer of, or of an authority on, a disease to that disease has been duly followed by the title of 'Wilms' tumour.' In an attempt to conform with this custom while giving the simplest possible description compatible with known facts it has been decided in the present paper to refer to the tumours as 'Wilms' embryomata.'

Although these tumours are among the commonest of malignant growths in children, there has been only one large series which has been reported from this country, that of McCurdy (1934), who studied thirty-one renal tumours of which twenty-seven were 'nephroblastomata.'

In America, on the contrary, much interest has been shown in them especially from the point of view of prognosis and treatment. Priestley and Broders (1935) reviewed sixty-five cases treated at the Mayo Clinic, of which forty-four were followed up. Only two patients were older than fourteen years of age. Of the forty-four patients traced forty had died. Nephrectomy had been performed in twenty cases and of these fifteen had died. One had survived 13.2 years and one 3.2 years after operation. The other two had been operated on only six months previously. One case was not traced. Not one patient treated by radiation alone had survived. However, of Poule and Ritchie's six cases (1935) the only one still alive (three-and-a-half years after operation) had received x-ray treatment alone. 
In 1931 Prather and Crabtree published four of their own cases and reviewed all the cases reported since 1924, a total number of $111 ; 70$ per cent. of these proved fatal within fifteen months of the onset ; 12.3 per cent. survived surgery two or more years ; whilst 18.4 per cent. died within one month of operation.

Geschickter and Widenhorn (1934) reported thirty-five cases, thirty of which were under five years of age. One patient was an adult. They followed up twenty-five cases and found not one alive beyond the five-year period. Most of them died or showed metastases within two years.

Wollstein (1927) made a careful clinico-pathological study of seventeen ' embryonal adeno-sarcomata.' One patient survived into adult life and was still alive thirty years after operation. Two others were alive ten months and six-and-a-half years after operation.

Dean and Pack (1932) collected sixteen cases of 'nephroblastomata' in which the average duration of life after nephrectomy was nine months. One patient survived three years and another two years after the onset of symptoms. No permanent cures occurred.

From these melancholy figures it follows that the prognosis in any individual case appears to be a gloomy one. It is impossible to predict either from the age of the child or the histological appearance of the tumour which child is likely to survive.

\section{Clinical aspects}

The series described in this paper consists of twenty-six cases from the post-mortem records and case notes of the years 1921-37 inclusive. One of these (No. 1) is of special interest and is being reported fully by Dr. D. N. Nabarro. We are indebted to him and also to Mr. C. Donald, under whose care the patient was, for their permission to include it in this series for statistical purposes.

In the corresponding period there were only five other tumours primarily renal in origin. Histologically three were sarcomata, one was a carcinoma and the fifth was not identifiable.

In ten of the cases an autopsy was performed (three autopsies in which the sections were not available have not been included). In the remainder the diagnosis was made by examination of the tumour after removal or of material obtained by biopsy. Ten of the patients were males and sixteen females. The age incidence is shown in the following table :

$\begin{array}{llllllllllll}\text { Age in years } & . & \ldots & 0-1 & 1-2 & 2-3 & 3-4 & 4-5 & 5-6 & 6-7 & 7-8 & 8-9 \\ \text { No. of cases } & . . & \ldots & 3 & 5 & 7 & 4 & 4 & 0 & 1 & 1 & 1\end{array}$

From this it is seen that nearly half of the total number occurred in the second and third years. There were three children of less than one year of age and one was only two months old. Only three tumours were found in children over five years of age.

Presenting symptoms.- In the table below, the presenting symptoms are analysed. It was not always possible to discover what these were, as in some instances the history was very vague.

The commonest mode of onset is, therefore, a progressive enlargement of 
the abdomen. It should be mentioned here that in several cases there was, on admission, a considerable degree of abdominal enlargement which had not been noticed by the parents.

Haematuria was an infrequent symptom. As a presenting symptom it occurred in only four cases; two of these were sent into hospital with a diagnosis of acute nephritis. In a fifth case there was haematuria twice late in the course of the disease. Many writers have emphasized the infrequency of haematuria in this class of tumour. Occasionally, as in Bothe's patient (1931), who had nine attacks of painless haematuria, it is a prominent symptom.

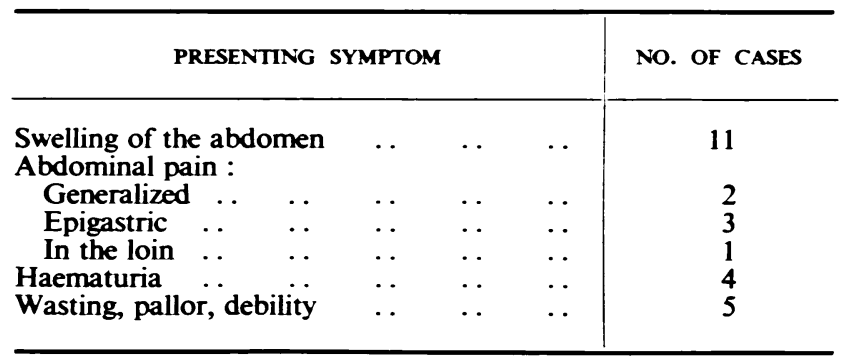

The onset of these neoplasms was, therefore, in most cases insidious and the tumour had usually reached a considerable size before the patient came to the doctor. In seven cases, however, the onset was more acute. In three of these there was sudden onset of haematuria (see table); in two others there was a recent history of vomiting with the passage of blood in the stools, and in the remaining two, abdominal pain.

Little information about the blood picture is available in this series. Only six patients had their blood examined. Five were anaemic, three severely. In four the colour index was below unity; in the other it was $1 \cdot 1$. There were no nucleated red cells in the peripheral circulation in any of the five. There were no significant changes in the leucocyte count.

Pyrexia was not a feature of the clinical course, a fact which contrasts with a recently recorded series of sympathoblastomata (Stern and Newns, 1937). In three patients there were occasional rises of temperature to $101^{\circ}-102^{\circ} \mathrm{F}$. lasting for two to three days, but there was no persistent raising of temperature nor any type of periodic fever.

Results of operation. - In sixteen cases it was possible to remove the tumour. Two patients died within a short time of admission before a nephrectomy could be performed ; in two others no operation was attempted ; and in the remaining six cases the tumour was found to be inoperable, either because it was too large and too adherent or because of secondary deposits.

Of the patients who had nephrectomies one died shortly after the operation, six within a few months, two others were discharged almost moribund, and four are still alive. The remaining two were untraced. Two patients received deep $x$-ray therapy following nephrectomy. One of these is still alive nine months afterwards. 
WILMS' EMBRYOMA

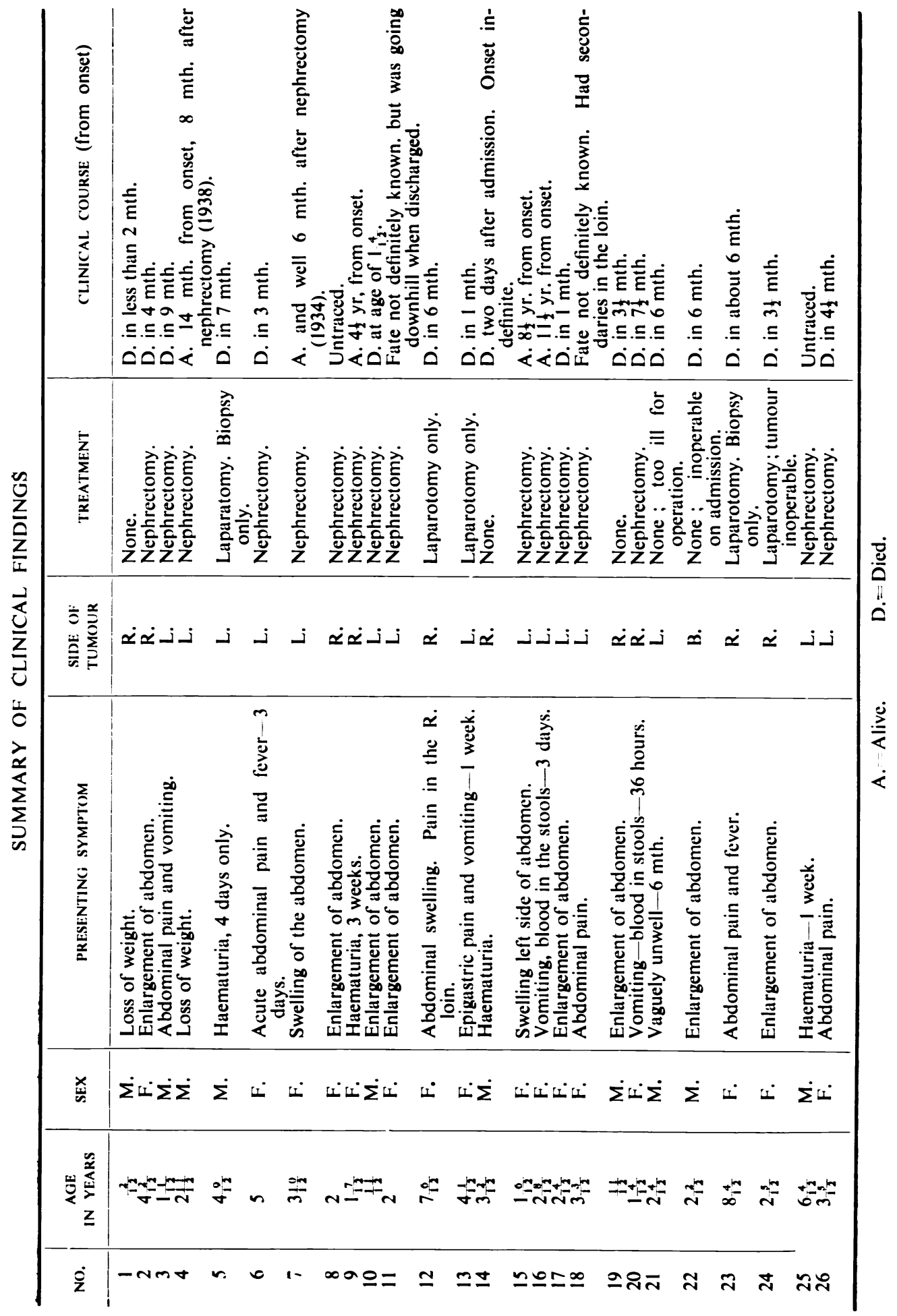

음

के

$\vec{\circ}$ 
Duration of life. - Of those known to have died only three lived for more than six months after the appearance of the first symptoms, the longest period being nine months. The average was five months. Several died within three months of the onset. The fate of five patients could not be traced. Two of these had extensive secondaries on discharge and may be presumed to have died soon after, and another was alive and well six months after nephrectomy in 1934; four children are known to be alive, one four years after operation, another eight years, and another eleven years, while the most recent case is still alive nine months after nephrectomy.

Diagnosis. - The diagnosis in most cases is easy. The tumour in one or other flank is usually easily palpable. It may be confused with unilateral hydronephrosis, especially if this is very tense. Pyelography will generally exclude hydronephrosis. It may sometimes be difficult to distinguish a Wilms' embryoma from a suprarenal sympathoblastoma. In the latter the growth tends to extend more to the mid-line and is more fixed. There are often secondaries either in the liver or bones, especially those of the skull. If bony metastases are present a diagnosis of sympathoblastoma may confidently be made, as the renal tumour hardly ever metastasizes in bone. Dean and Pack (1932), however, reported two cases in which metastases had occurred in the scapula, parietal bones and ileum.

Treatment.-The tumour is in most cases well encapsuled and not very adherent to surrounding tissues. Removal is, therefore, not difficult. Unfortunately recurrence is very common. The site is usually in the operation bed, but metastases in the viscera, for example the liver and lungs, occur in some 20 per cent. of cases. Lately, especially in America, it has been the practice to irradiate the growth before and after operation. The Wilms' embryomata are very radio-sensitive and diminish considerably in size as a result of $x$-ray therapy (Dean and Pack, 1932). Thorough treatment of this kind, therefore, might diminish considerably the proportion of recurrences.

\section{Morbid anatomy}

The tumour was on the left side in fifteen cases, on the right in ten and in one both kidneys were stretched over a large tumour. These growths are usually solid, encapsulated, and press upon rather than invade the kidneywhich is, however, often compressed into a thin sheet or strip stretched over the tumour. On section fibrous septa may be seen dividing the tumour into lobules, but these are not constantly present. The consistency is not uniform ; in the same tumour may be found dense fibrous areas, parts firm and elastic, massive areas of haemorrhage, recent or of some duration, with soft, gelatinous areas surrounding the haemorrhages. The confluent necrotic areas which are seen in most tumours of the sympathetic nervous system arising from the suprarenals were not present in this series of Wilms' embryomata.

Two tumours were cystic. Projecting into the cavity of one was a large, papilliferous tumour mass. A smaller ingrowth from the wall of the cyst was solid and had a smooth surface. The cyst appeared to grow from the region 
of the pelvis of the kidney, but histologically the solid parts of the tumour were indistinguishable from other tumours in this series (see fig. 2, 3 and 4). The other contained thick grumous material, probably a degeneration product, while the only solid parts of the tumour were at the periphery of the cyst where haemorrhagic and semi-solid tumour substance could be recognized. Only the upper pole of the kidney could be identified, but between this and the tumour cyst was a fibrous capsule. The more solid portion showed the microscopical appearances of a typical Wilms' embryoma.

Direct extension of the growth was observed in one of the cases which came to post mortem and in one operation case. In the former the growth extended

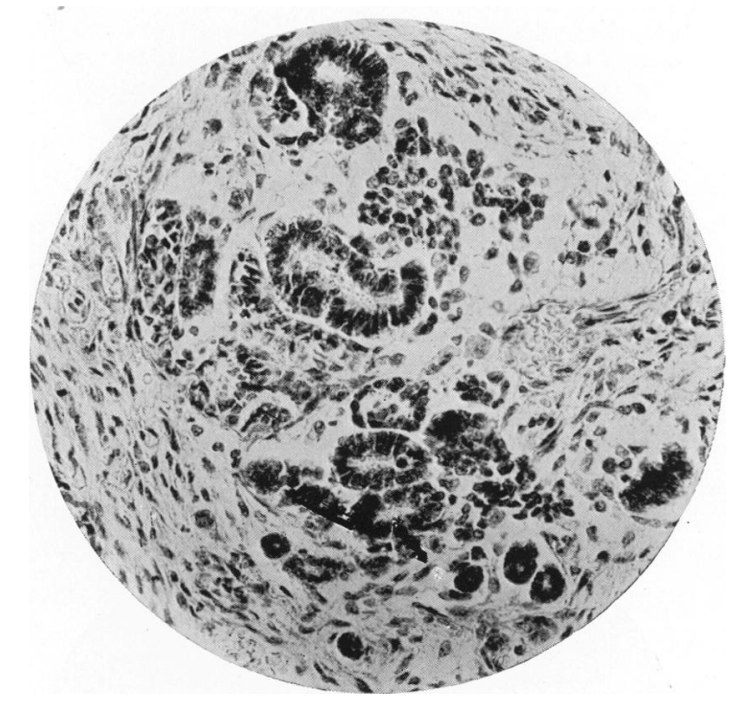

FIG. 1.-A representative section from case 6. Numerous tubules varying greatly in size and shape are present. Some have practically no lumina. On the left is a band of spindle cells running almost vertically. Two groups of small undifferentiated cells may also be seen. (Stain : Haematoxylin and Van Gieson; $\times 220$.)

not only into the renal vein but also up into the inferior vena cava. Mr. O. L. Addison, F.R.C.S., operated on the other case and has kindly furnished details of his operative findings. The growth extended around and down the upper part of the ureter. The diseased portion of the ureter was removed together with the kidney and the growth, but it is certainly surprising that the child is still alive four-and-a-half years after operation, especially as no subsequent $\mathrm{x}$-ray treatment was given.

Metastases in the glands directly draining the renal area were present in twelve of the twenty-six cases. It is obviously idle to speculate on the likelihood of visceral metastases in cases in which no post mortem was held; it is only possible to mention if enlarged or obviously invaded glands were noted by the surgeon at operation. At post mortem visceral metastases were commonest in the lungs; they were present in three cases of the ten which came to autopsy. 


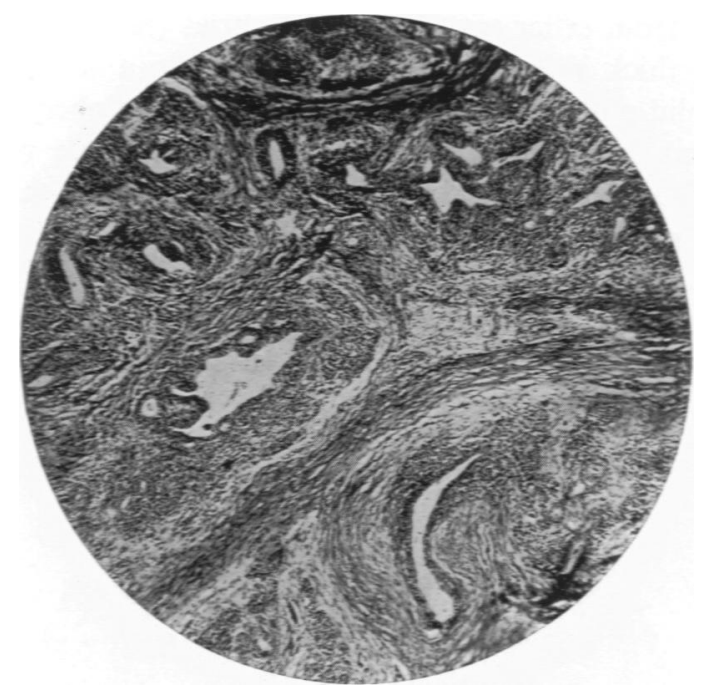

FIG. 2.-Low-power view of tumour from case 15. (Child alive eight years after operation.) Many tubules, some dilated, are seen surrounded by small undifferentiated cells. A broad band of connective tissue passes right across the section. (Stain : Haematoxylin and Van Gieson ; $\times 50$.)

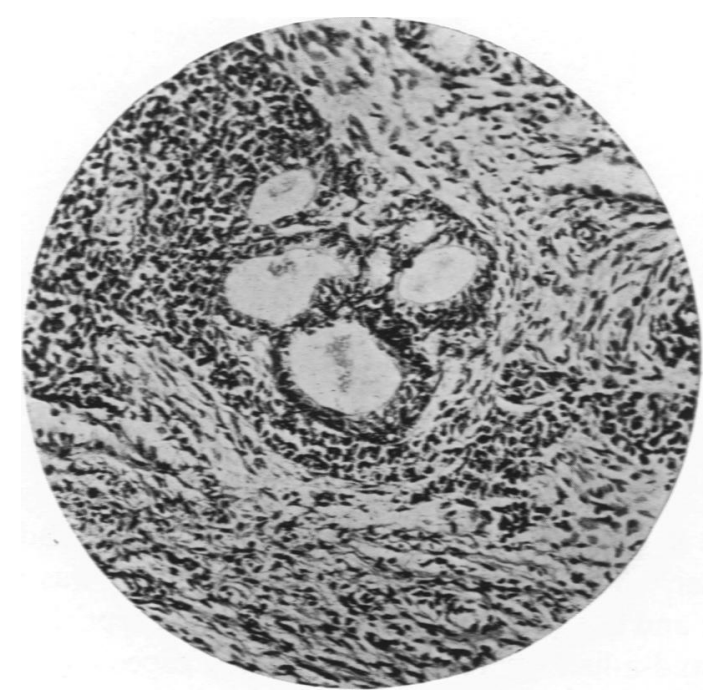

Fig. 3.-Higher power view of tubules from same tumour. A group of tubules merges into a mass of small undifferentiated cells. The tubules are lined by a low cubical epithelium and in several of them there is reduplication of the lining cells. A definite basement membrane is present. Several of the tubules contain hyaline material. (Stain : Same as fig. $2 ; \times 150$.) 


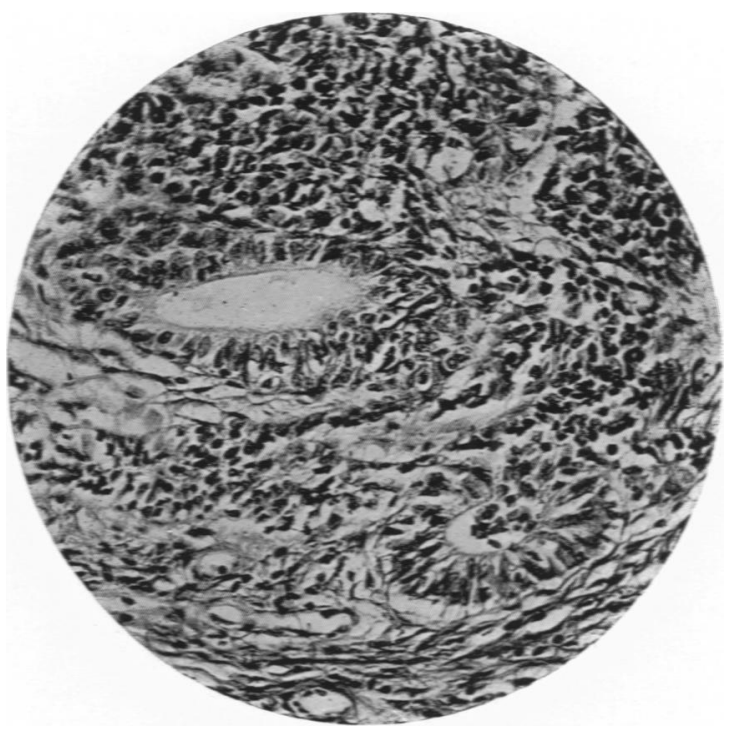

FIG. 4.-High-power view of tubules in another section from same case showing proliferation of layers of cells lining the tubules and a columnar type of epithelium. (Stain : Same as fig. $3 ; \times 225$.)

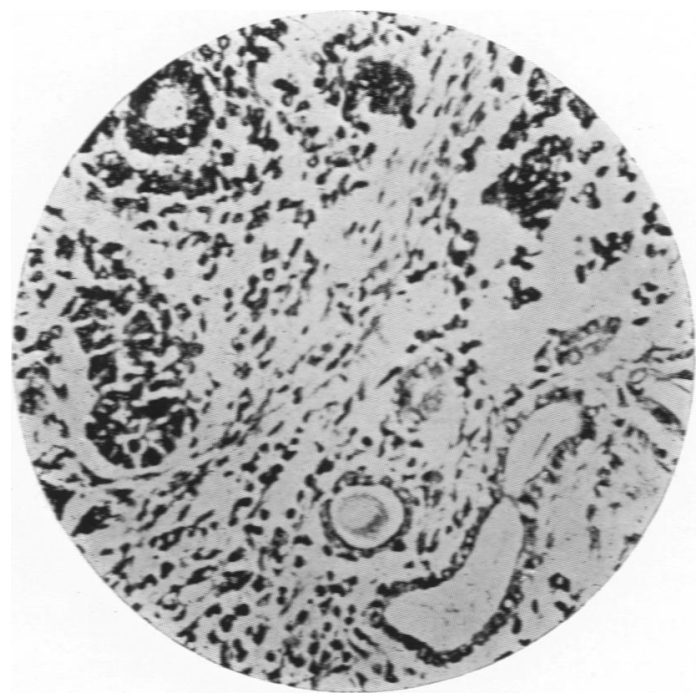

Fig. 5.-Section from case 19 to show two types of tubule. The two lower tubules are lined by a single layer of cubical epithelium and one of them contains hyaline material. The two upper tubules have a taller epithelial lining and this is several layers in thicknesssee fig. 6. (Stain : Haematoxylin and eosin ; $\times 150$.) 
In two cases in which operation was performed the symptoms and $\mathrm{x}$-ray findings left no doubt that the lungs were invaded by secondary deposits. One of these children died seven-and-a-half months after operation; the other could not be traced, but he left hospital in such a poor condition that he was not expected to survive more than a few weeks. Tiny metastases barely visible to the naked eye were found in the liver at post mortem in two cases. The diaphragm was observed to be invaded by growth in one case at post mortem and in one case at operation. These findings confirm those of other authors that visceral metastases are relatively uncommon. In Wilms' review of the

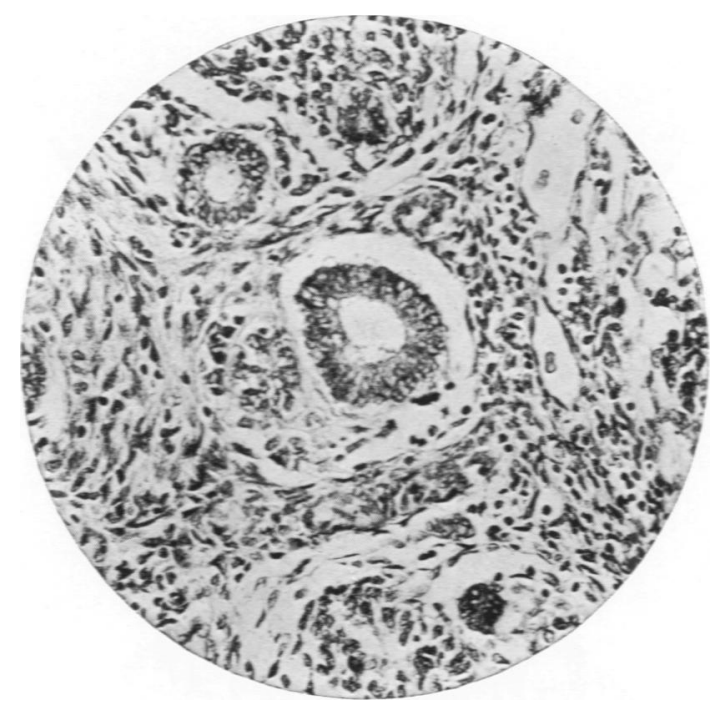

FIG. 6.-High-power view of cne of the tubules seen in fig. 5. Reduplication of the cells lining the tubule can be seen. A definite basement membrane is present. Spindle cells and small round cells surround the larger tubule forming a kind of " capsule " in which the tubule lies. (S:ain : Same as fig. $5: \times 220$.)

literature he found visceral metastases in 30 per cent. of cases. Lyman (1925) put the figure as high as 50 per cent., whereas Wollstein's figures were three out of seventeen.

Histological findings. - In nine tumours of the series sufficient material was available for a detailed study of the histology. That is to say, sections taken from various parts of the tumours were stained by a variety of methods, including iron haematoxylin with Van Gieson's counterstain and Foot's method for reticulum, in addition to the routine method of haematoxylin and eosin. In the other cases sections stained by the routine method only could be studied, but as a rule several different sections were available from each case, enabling a fairly representative picture of the particular tumour to be reconstructed.

The general characteristics of the tumours differed little from those which have previously been recorded. Although the histological appearances varied in different parts of the tumours it was possible in almost every case to find one 
or two areas which served to identify them as embryomata. The most common picture was that in which solid, irregular masses of undifferentiated spindle cells, oval cells or round cells with little cytoplasm lay in a loose fibrillar matrix, the masses teing separated one from the other by strands of connective tissue. In sections stained with Fcot's reticulum stain it was possible in some cases to demonstrate fine reticular fibrils between the cells, especially when these were arranged somewhat loosely. The arrangement of these masses of undifferentiated cells varied from case to case. Sometimes they were arranged in a lobulated pattern, sometimes there was little connective tissue present and the masses of cells gave an appearance strongly suggestive of a sarcoma. In the midst of these undifferentiated cells various types of tubule were found on which the diagnosis of embryoma was based. In some cases tubules were numerous; in others they were scanty and few would be seen in one section. There was great variety in the size and shape of these tubules. Fig. 1 is representative of the common forms observed. In this tumour most tubules were lined by one or more layers of columnar epithelium. Many were twisted, giving a U-shaped appearance. The difference in size is well seen in the photomicrograph. Some of these tubules contained granular material staining yellow in Van Gieson's stain and pink in eosin. The tubules possessed a definite basement membrane. In some there was a ' heaping up ' of proliferating epithelial cells at one side of the tubule, as for example in fig. 4. Cystic dilatations were not usually observed in this type of tubule. Other types are shown in figs. 2, 3 and 5. In these, cystic dilatation was common and the dilated tubules often contained masses of hyaline material. The epithelium of these tubules was cubical in shape and only rarely was it more than one layer in thickness. Tubules with low cubical epithelium were found singly rather than in groups. The appearance shown in fig. 3 was therefore the exception rather than the rule. Fig. 5, which shows two isolated tubules with flattened epithelium, one containing a hyaline mass, is much more typical. So far, the histological findings agree with those of McCurdy and others who have described the characteristic tubules of these tumours. Where the findings in the present series differ is in the almost complete absence of striped muscle fibres. In spite of careful scrutiny of a number of sections we were able to find definite smooth muscle fibres in only one case (no. 16). In this, diligent search revealed a small bundle of smooth muscle fibres. As the percentage of cases in which smooth muscle fibres are present has been variously estimated from 10 to 37 (McCurdy), we are quite at a loss to explain their absence in our series. Primitive glomeruli were uncommon. They were best seen in the case of the three-month-old baby which is being reported separately by Dr. D. N. Nabarro.

Histological examination of the metastatic deposits in the lungs and liver showed only undifferentiated spindle-cells and small round cells with scanty cytoplasm, many of which were undergoing mitosis. A variable amount of fibrous tissue was present in these deposits, but the characteristic tubules could nowhere be seen. 


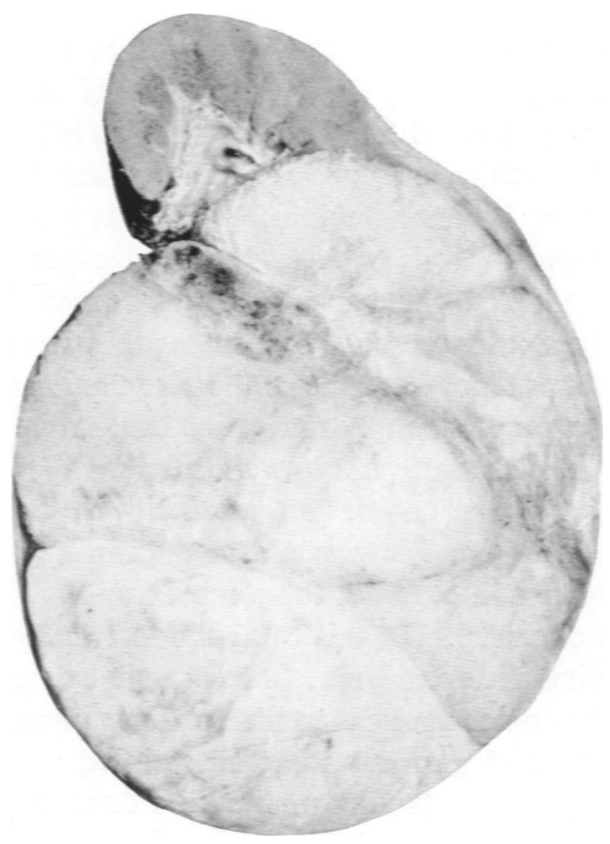

FIG. 7.-Case 16 : solid fibrous-looking tumour with the lower part of the kidney stretched out over the surface. The child is alive eleven years after nephrectomy.

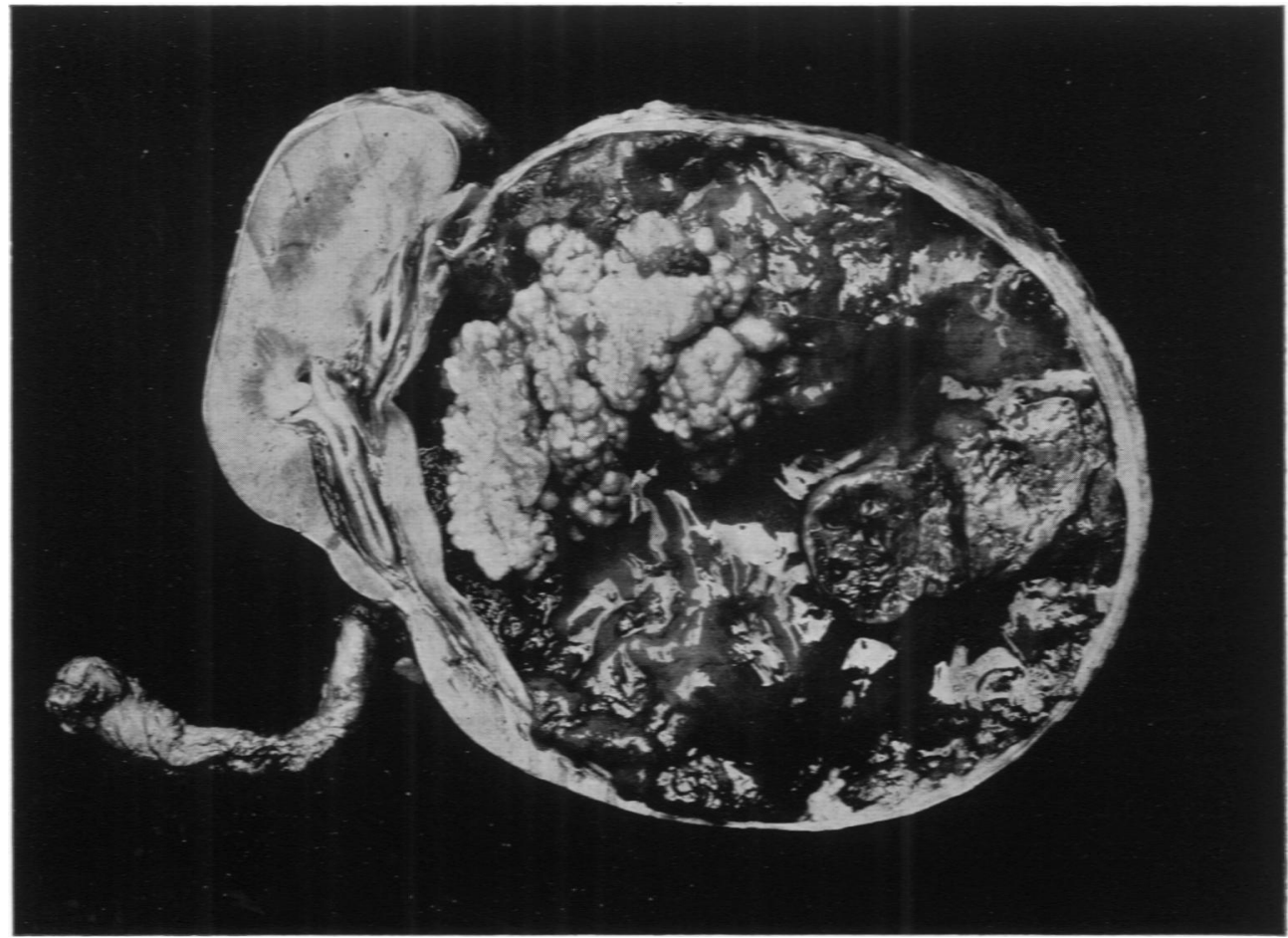

Fig. 8.-Case 15 : one of the two cystic tumours into which there projects a large papilliferous ingrowth. The kidney lies to the left of the cyst. This child is alive eight years after nephrectomy. 


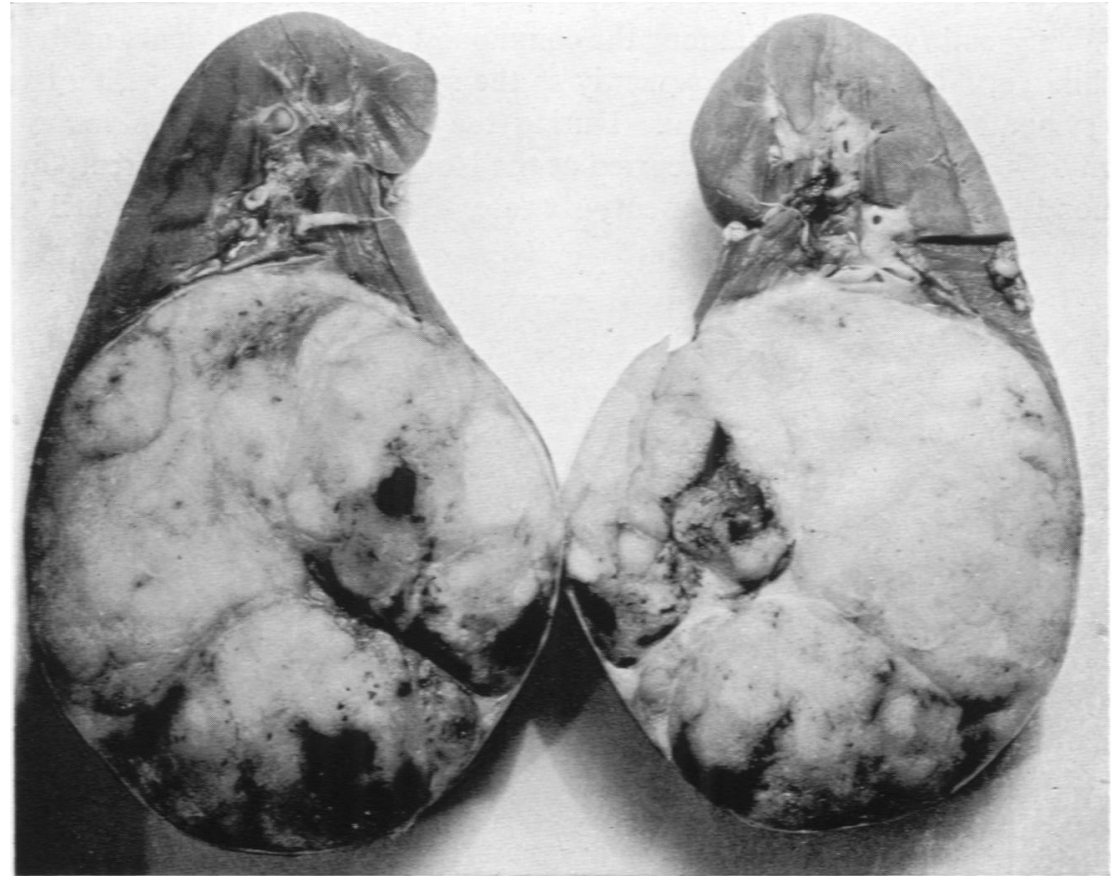

Fig. 9.-Case 3 : firm solid tumour into which haemorrhages have occurred. The child died within a few months of operation.

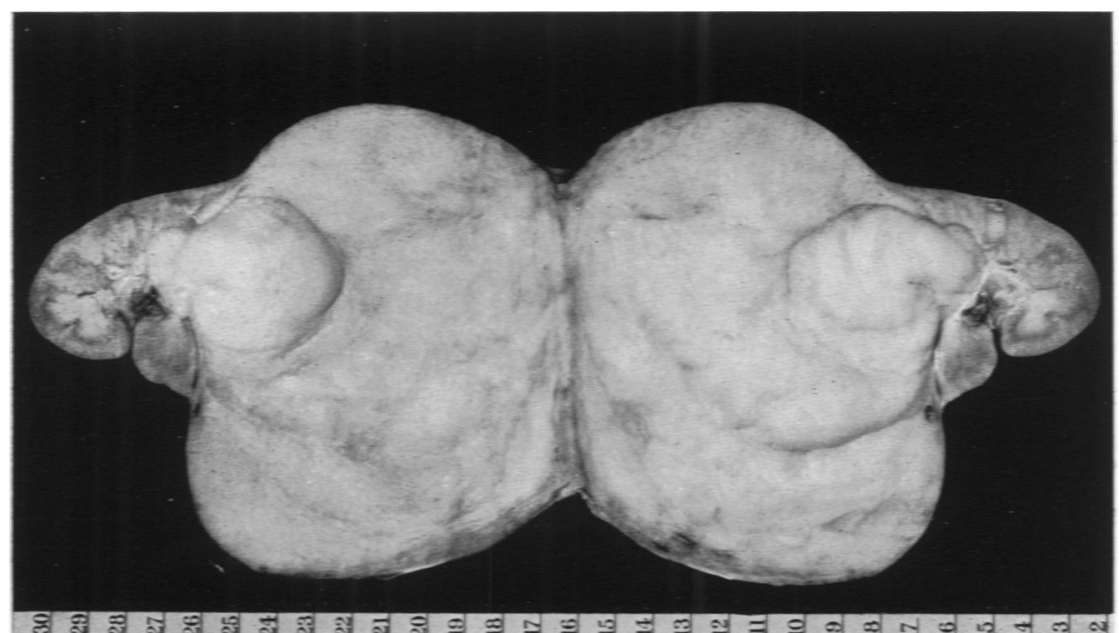

FIG. 10.-Case 4 : solid fibrous-looking tumour. Child still alive eight months after nephrectomy. 


\section{Discussion}

Wilms' embryomata are among the commonest malignant tumours met with in children. They occur as frequently as the sympathoblastoma arising from the sympathetic nervous system. During the years 1921 to 1936 inclusive twenty-five cases of the latter occurred at the Hospital for Sick Children, Great Ormond Street. The series of twenty-six cases described in this paper includes

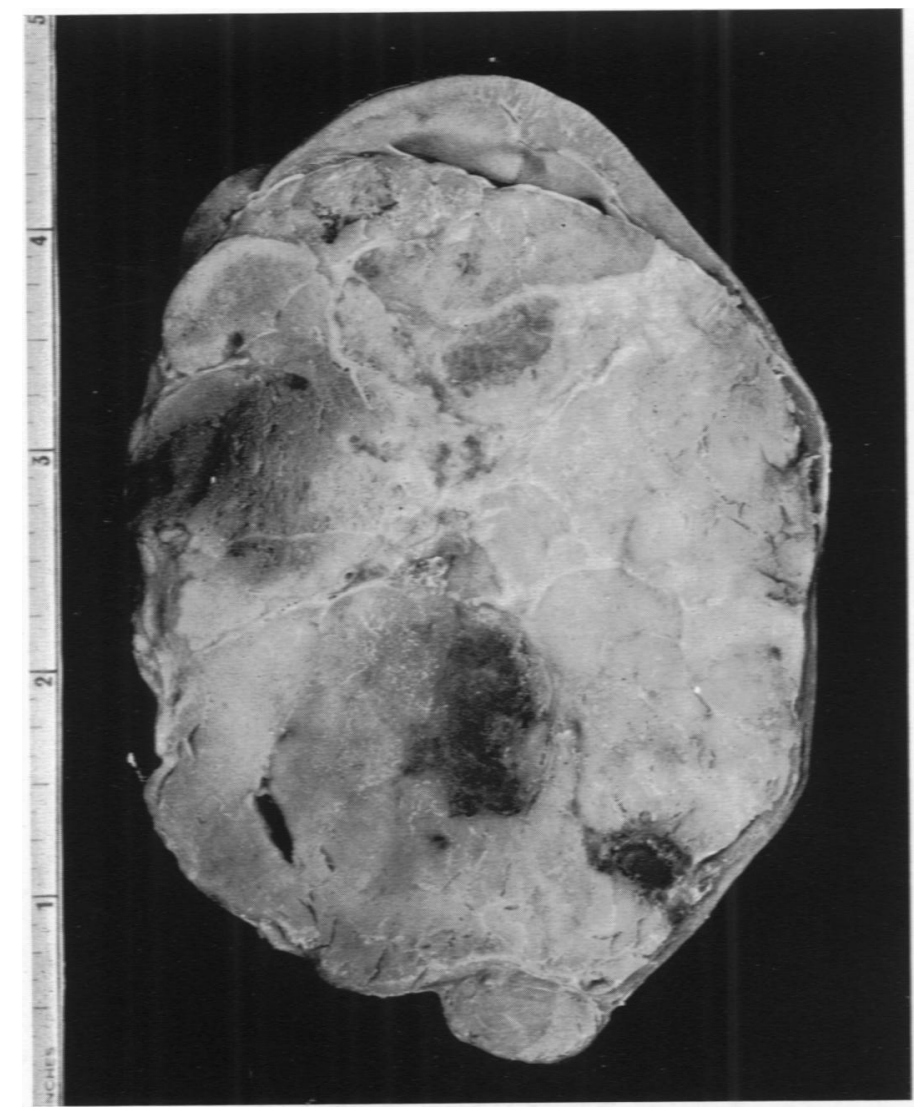

FIG. 11.-Case 6: gelatinous tumour with many fibrous septa and containing areas of haemorrhage.

the year 1937. These figures contrast with those for other types of malignant abdominal tumours, of which only four examples were traced over the same period. These were diagnosed as retroperitoneal sarcomata, and histological examination confirmed this diagnosis.

The onset is usually insidious and the disease may be far advanced before the patient is brought to the doctor. Enlargement of the abdomen is the commonest presenting symptom, but haematuria is uncommon either as an early or late symptom. This observation has teen made by many writers and is 
explained by the fact that the kidney is compressed but rarely invaded. The tumour was in most cases well encapsuled and easily removable.

Unfortunately in many of the patients there was a recurrence of the tumour

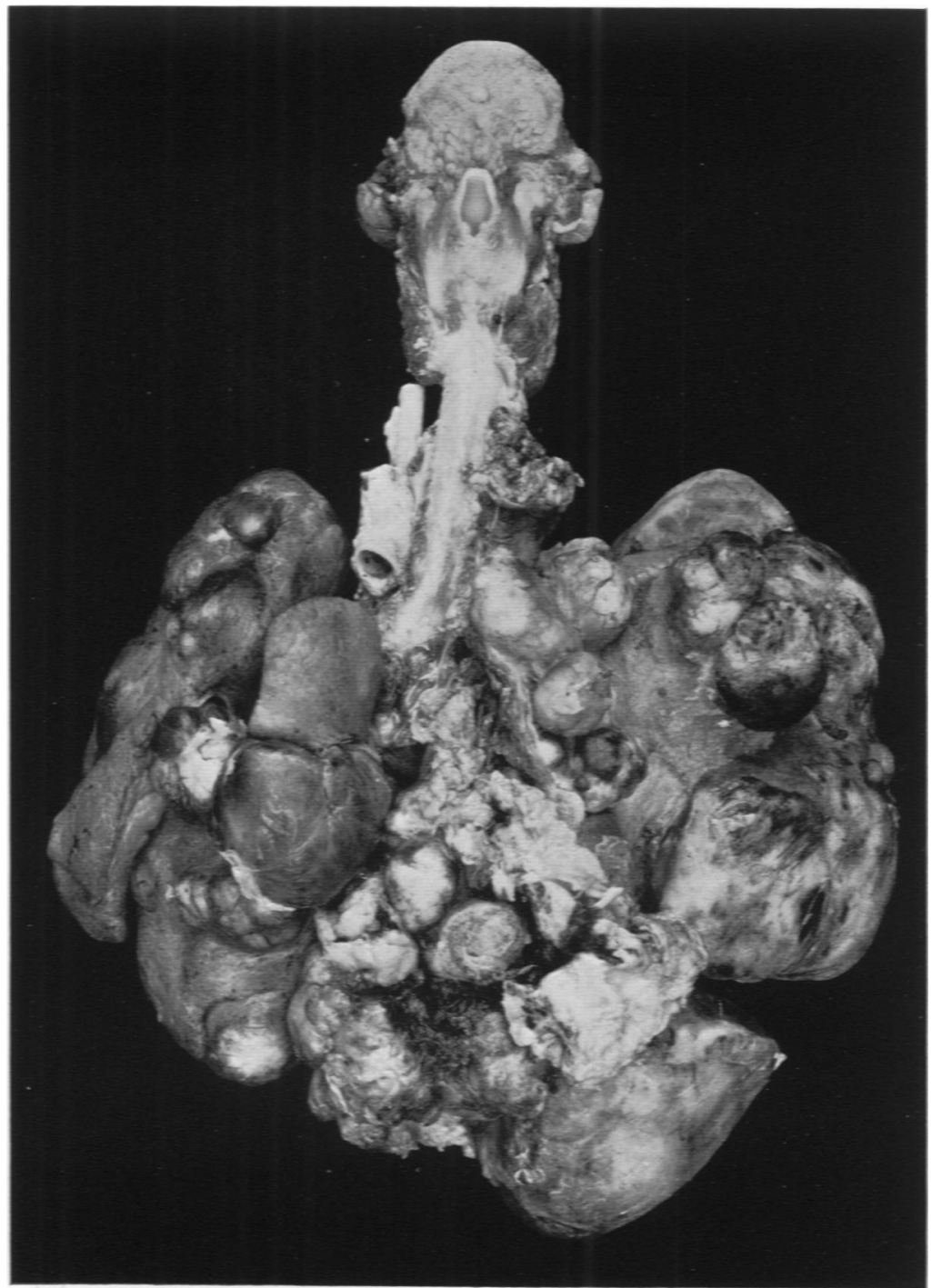

Fig. 12.-Case 6 : thoracic viscera showing massive secondary deposits in the lungs.

within several months after operation. These recurrences were usually in the loin or neighbouring lymphatic glands and in a few cases in the viscera, especially the lungs and liver. Of the sixteen patients who had a nephrectomy, four are still alive eleven years, eight-and-a-half years, four-and-a-half years, and eight months respectively after operation. The first three patients may reasonably 
be considered cured. It is too early yet to say whether in the remaining one there will be a recurrence. This patient had post-operative $x$-ray therapy; the others did not. This recovery rate compares favourably with that of 12.3 per cent. in the review by Prather and Crabtree of one hundred cases, and is decidedly better than that of Geschickter and Widenhorn, who followed

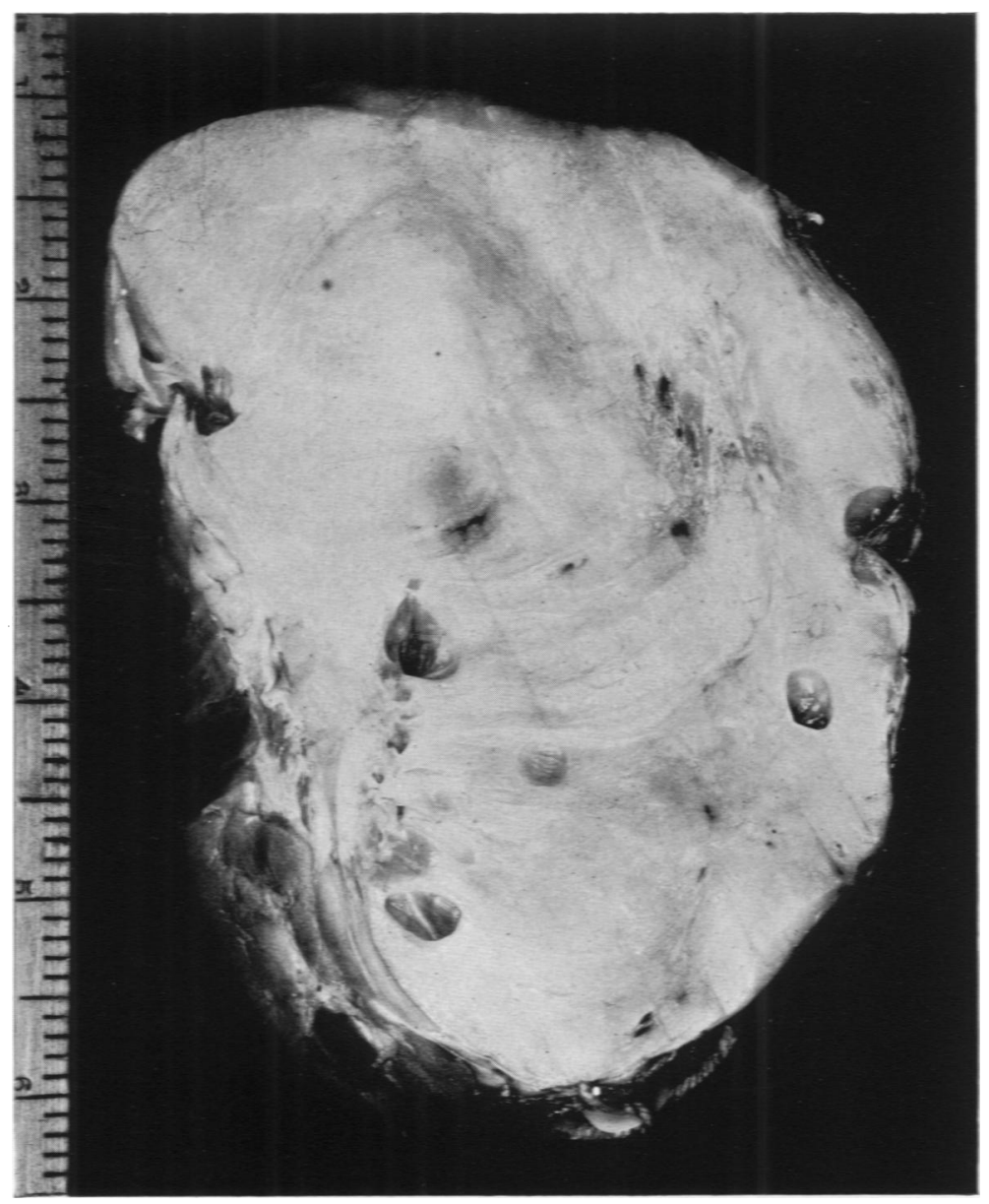

FIG. 13.-Specimen removed after seventeen doses of deep x-ray therapy. Notice the fibrous appearance of the tumour. (Photograph from a private case reproduced by courtesy of Mr. T. T. Higgins.)

up twenty-five patients and found not one alive five years after operation. Work in America has raised the hope that better results might be obtained by irradiation of the tumour both before and after nephrectomy. There is no doubt that these tumours are very radio-sensitive and will shrink considerably in size after exposure to deep x-rays. Mr. T. T. Higgins, F.R.C.S., has kindly allowed us to quote a case of his which had seventeen treatments with deep $x$-ray 
therapy followed by nephrectomy. The appearance of the tumour (fig. 13) was very fibrous and on section dense fibrous tissue had completely replaced the tumour cells.

\section{Summary}

(1) A series of twenty-six cases of Wilms' embryoma of the kidney is described covering a period of seventeen years.

(2) The tumours were one-and-a-half times as common in females as in males. All but three of the patients were below the age of five years and fifteen were under three years.

(3) The growths were commoner on the left than on the right. One occupied a median position and had both kidneys stretched over it.

(4) The onset was in most cases insidious, the commonest presenting symptom being enlargement of the abdomen.

(5) In seven cases the onset was acute or subacute.

(6) Visceral metastases were uncommon, occurring in only a third of the patients who came to autopsy, and these were not extensive.

(7) The results of nephrectomy in this series are encouraging, as of the sixteen patients operated on, four are still alive.

(8) It is suggested that a more hopeful prognosis may be given if patients are subjected to nephrectomy preceded and followed by deep x-ray therapy.

It is a pleasure to thank Dr. D. N. Nabarro, Director of the Pathological Department, for his advice and encouragement. We are grateful to the Honorary Staff of the Hospital for permission to use their case records and especially to Mr. T. T. Higgins for kindly furnishing us with additional details of several cases. To Mr. Addison, Honorary Consulting Surgeon, who operated on many of the cases recorded, we are particularly indebted for information about the subsequent history of his cases. All the photographs were taken by Mr. D. Martin, who has also helped considerably in collection of material for the pathological part of this paper, for which we thank him.

\section{REFERENCES}

Birch-Hirschfeld, F. V. (1898). Beit. path. Anat., 24, 343.

Bothe, A. E. (1931). Surg. Clin. N. Amer., 11, 1,471.

Busse, O. (1899). Virch. Arch., 157, 346.

Coley, W. B. (1935). Amer. J. Surg., $29,463$.

Dean, A. L., and Pack, G. T. (1932). J. Amer. med. Ass., 98, 10.

Eberth, C. J. (1872) (quoted by Wilms). Virch. Arch., 55, 518.

Geschickter, C. F., and Widenhorn, H. (1934). Amer. J. Canc., 22, 620.

Heineke (1897) (quoted by Wilms). Inaug. Diss. Münch.

Ingram, D. N. (1936). Amer. J. Surg., 32, 366.

Kretchmer, H. L., and Hibbs, W. G. (1931). Surg. Gynec. \& Obst., 52, 1.

Lyman, G. D. (1925). Arch. Ped., 42, 96.

McCurdy, G. A. (1934). J. Path. Bact., 39, 623.

Nicholson, G. W. (1931). Ibid., 34, 711.

Perthes, G. (1896). Deut. Ztschr.f. Chir., 42, 201.

Pohle, C. A., and Ritchie, G. (1935). Radiology, 24, 193. 
Prather, G. C., and Crabtree, E. G. (1931). J. Urol., 25, 589.

Priestley, J. T., and Broders, A. C. (1935). Proc. Staff Meet. Mayo, Clin., 10, 81. - (1935). J. Urol., 33, 544.

Ribbert, H. (1886) (quoted by Wilms). Virch. Arch., 106, 282.

Sinkoe, S. J., Fowler, M. F., and Berger, L. (1934). Amer. J. Surg., 25, 163.

Stern, R. O., and Newns, G. H. (1937). Arch. Dis. Childh., 12, 267.

White, W. M. C. (1931). Ann. Surg., 94, 139.

Wilms, M. (1899). '“ Die Mischgeschwülste der Niere,” Leipzig.

Wollstein, M. (1927). Arch. Path., 3, 1. 